\title{
DOPAMINE DYSREGULATION SYNDROME IN PARKINSON'S DISEASE
}

\section{Case report}

\author{
Arthur Kummer' , Débora Palma Maia², João Vinícius Salgado3, \\ Francisco E.C. Cardoso ${ }^{4}$, Antonio Lucio Teixeira ${ }^{5}$
}

\begin{abstract}
We report a 67-year-old man with Parkinson's disease for 9 years who developed compulsive use of levodopa. This phenomenon is the main feature of the dopamine dysregulation syndrome. Other related symptoms presented by our patient were mood fluctuation and increased writing activity suggestive of punding.

KEY WORDS: Parkinson's disease, dopamine dysregulation syndrome, punding.
\end{abstract}

\begin{abstract}
Síndrome de desregulação dopaminérgica na doença de Parkinson: relato de caso
RESUMO - Relatamos sobre um homem de 67 anos de idade com doença de Parkinson por 9 anos e que desenvolveu uso compulsivo de levodopa. Esse fenômeno é a principal característica da síndrome de desregulação dopaminérgica. Outros sintomas apresentados pelo paciente foram flutuações do humor e atividade de escrita aumentada, comportamento este sugestivo de punding.
\end{abstract}

PALAVRAS-CHAVE: doença de Parkinson, síndrome de desregulação dopaminérgica, punding.

Parkinson's disease (PD) is associated with a progressive dysfunction of the dopaminergic neurotransmission in the basal ganglia. On pathological examination, the dopaminergic neurons in the pars com pacta of the substantia nigra a re markedly reduced, and cytoplasmic proteinaceous aggregates known as Lewy bodies are present in the residual neurons. Dopamine replacement therapy (DRT), with the dopamine precursor levodopa or synthetic dopamine agonists, is considered the mainstem of the pharmacological approach for the symptoms of PD ${ }^{1,2}$. However long-term DRT is commonly associated with a series of motor complications, such as dyskinesias and the on-off phenomenon. More recently, interest has been drawn to non-motor complications of PD and treatment-related psychiatric symptoms, such as depressive disorders, fatigue, apathy and cognitive impairment $^{3}$.

We describe a man with PD since 58 year-old who developed compulsive use of levodopa. In off peri- ods he presented severe non-motor symptoms, including craving for levodopa, intense feelings of dysphoria, worsening of depressive symptoms, painful trunk sensations and profuse sweating. During peak dose period, he also became hypomanic and had difficulty in perceiving his severe dyskinesias. This behavior has been recently described in literature as a quite ra renon-motor complication of DRT. This syndrome of increased use of levodopa beyond that needed to achieve relief of motor symptoms, associated with disabling mood and behavioral features is referred by some authors as dopamine dysregulation syndro me (DDS) ${ }^{4,5}$. To the best of our knowledge, this is the first case of this syndrome reported in the Brazilian literature The patient gave informed consent for this case report.

\section{CASE}

A 67-year-old man, married, a retired surgeon had PD for 9 years. He had no previous history of alcohol or any

\footnotetext{
${ }^{1}$ Médico Psiquiatra; ${ }^{2}$ Médica Neurologista; ${ }^{3}$ Médico Psiquiatra, Professor da Universidade Fumec; ${ }^{4}$ Coordenador da Clínica de Distúrbios do Movimento do Hospital das Clínicas da Universidade Federal de Minas Gerais, Belo Horizonte MG, Brazil (UFMG). Professor Adjunto do Departamento de Clínica Médica da Faculdade de Medicina da UFMG; ${ }^{5}$ Médico Neurologista e Psiquiatra, Professor Adjunto do Departamento de Clínica Médica da Faculdade de Medicina da UFMG.
}

Received 22 February 2006, received in final form 13 June 2006. Accepted 25 July 2006.

Dr. Antonio Lucio Teixeira - Departamento de Clínica Médica, Faculdade de Medicina / UFMG - Avenida Prof. Alfredo Balena 190 30130-100 Belo Horizonte MG-Brasil. E-mail: altexr@gmail.com 
drug abuse and his past history was unremarkable. There was no familiar history of psychiatry or neurological diseases. His first parkinsonian symptoms were rigidity and bradykinesia in his left hemibody. At first he was controlled with trihexifenidil and amantadine. These symptoms worsened pro g ressively and new ones appeared, such as mild rest tremor and gait disturbance. Two years after the onset of the illness levodopa was started. Despite some improve ment of symptoms, he decided to quit his medical practice. Within 3 years of use of levodopa he develo ped wearing off, motor fluctuations and mild generalized choreiform movements at peak dose. He also complained of low back pain. These pain episod es were sparse, mild to moderate in intensity and tolerable. A careful work-up was performed to investigate this symptom, including magnetic resonance image of the thoraco-lumbar spine and electroneuromyographic studies of inferior limbs, and the exams were unrevealing.

In the following two years, motor fluctuations worsened considerably, requiring the optimization of treatment with pramipexole. The low back pain also became more intense and frequent, appearing several times a day during off periods. Non-steroidal anti-inflammatory drugs, analgesics, including opioids (tramadol), and tricyclic antidepressants were of no benefit in ameliorating pain. According to the patient only levodopa could bring symptomatic relief. Then he started using progressive larger doses of levodopa up to 30 tablets a day of levodopa/carbidopa $250 / 25$. As a consequence, he developed dramatic peak dose dyskinesias.

He was hospitalized. During levodopa washout, he presented only mild back pain despite evolving with marked bradykinesia. Of note he exhibited dysphoria and craving for levodopa, i.e. an impatient and an intense desire for it, and a dependence disorder was hypothesized. It was possible to adjust the dose of levodopa/car bidopa 250/25 to one tablet $3 / 3 \mathrm{~h}$. He was also using pramipexole $1 \mathrm{mg}$ QID, amantadine $100 \mathrm{mg}$ TID. Entacapone $200 \mathrm{mg}$ QID was added. Two months after hospital discharge he stopped taking entacapone and began the abuse of levodopa again. Then he was referred to our neuropsychiatric unit.

The patient confirm ed the high dose consum ption of levodopa. He justified this was the only way to be free of low back pain that had always appeared soon after levodopa effect faded. Furthermo re he was not bored by peak dose dyskinesias. He also complained about depressive symptoms, such as feelings of sadness, anhedonia, fatigue and reduced interest with social retraction. These symptoms were present for at least three years, but they were getting worse. He had used paroxetine irregularly without im p rovement in this period of time. He denied cognitive symptoms of depression, i.e. negativism or ideas of death. He was prescribed with sertraline $50 \mathrm{mg}$ a day and oriented to follow scheduled doses of levodopa/carbidopa 250/25, one tablet 3/3h, pramipexole $1 \mathrm{mg}$ QID and amantadine $100 \mathrm{mg}$ TID. He was also offered psychological support.

On subsequent evaluations, he denied misuse of levodopa, but he persisted with unaltered low back pain during off periods. These periods occurred approximately every two hours and half, and lasted 30 minutes. He noticed that feelings of sadness and apathy were more distressing during off episodes. Interestingly, sometimes he experienced feelings of euphoria with press u re of speech at the peak medication effect. Only mild generalized dyskinesias appeared with this therapeutic schema. Punding, an intense fascination with repetitive tasks, was suspected as the patient developed the habit of writing excerpts of his daily living. His writings were detailed, meaningful and with moral tones. Every day he wrote several pages just to throw them away. Then the diagnosis of DDS was established.

He did not show improvement in depressive symptoms with sertraline up to $100 \mathrm{mg}$ a day for 12 weeks. Thus bup ropion $150 \mathrm{mg}$ a day was tried as it has both noradrenergic and dopaminergic mechanisms of actions, but no change in depressive symptoms or craving for levodopa was noticed after 8 weeks. Entacapone $200 \mathrm{mg}$ QID was reintroduced in order to achieve more stable levels of levodopa but, again, there was no benefit. On one year follow-up he evolved with periods of exacerbation of low back pain when he abused levodopa for limited interval.

\section{DISCUSSION}

Long-temlevodopa therapy in PD is commonly associated with a series of motor complications, which include fluctuations or the on-off phenomenon and dyskinesias. Also as consequence of the treatment, some patients develop non-motor complications such as sleep disturbances, depressive disorders, mood fluctuations, anxiety, psychosis, stereotyped behaviors anddelirium ${ }^{3,6,7}$. Recently, it was associated with the compulsive use of levodopa (or other DRT) called by some authors DDS. In PD, the DDS is the equivalent of the hedonic or hedonistic homeostatic dysre gulation, a behavioral change initially described in association with addiction and substance misuse ${ }^{8-10}$. The core features of DDS are self-medication and levodopa-seeking and hoarding associated with disabling mood and behavioral changes. The later include pathological gambling, obsessional shopping, punding, hypersexuality, aggression and social isolation. Walkabouts are common and sometimes may last for hours $8,11,12$.

In the case reported, the patient developed severe non-motor symptoms with DRT. Initially he presented trunk pain that worsened specially during off periods. As he only achieved relief with levodopa, he began using pro g ressive larger doses of levodopa. His dramatic dyskinesias during on states did not discourage an escalation of doses, as they seemed not to bore him. It is common that patients who present DDS also have a marked alteration of the perception of the on state. They may develop severe but surprisingly well-tolerated drug-induced dyskinesias which 
do not act as a deterrent to further increases in the dosages of drugs $\mathbf{s}^{8,11,12}$.

When hospitalized and after levodopa washout, he became dysphoric and exhibited an intense desire for the medication. Though those symptoms may be co rrelated to mood fluctuation due to an intense off period, it may be considered a real withdrawal state commonly seen in other drugs dependence. Nevertheless, a withdrawal state from levodopa has not yet been confirmed ${ }^{13}$.

He had a minor depressive disorder which was lasting for three years. However, a mood fluctuation was perceived by the patient as his depressive symptoms became worse when medication wore off and he turned euphoric and felt a pressu reto speak during the peak dose. Also an abnormal writing activity was displayed. Automatic writing behavior has already been observed in PD and was also suggested to be punding ${ }^{14}$. Despite the writing hyperactivity of our case resembles more hypergraphia (detailed and meaningful) than automatic behavior, we hypothesized it would be another form of punding or any other repetitive behavior of PD.

The compulsive use of levodopa is a newly described syndrome associated with PD that has been in creasingly recognized. Two studies figured out the frequencies of DDS in PD between 3.4 and $4 \%{ }^{8,11}$. However these data may be biased as the population studied came from tertiary re fe rral centers. Since milder forms may occur, the real prevalence remains uncertain. Some risk factors are a previous history of mood disorders, the use of dopaminergic agents (specially chronic exposure to high doses of DRT), and possibly, other risk factor such as family history of psychiatric disorders and past history of alcohol dependence ${ }^{4,11,15}$. In the case reported, apart from the use of high doses of levodopa the patient had none of these risk factors. Some personality traits were also linked to DDS like the high novelty seeking and the low harm avoidance traits ${ }^{15}$. These personality traits would not be adequate to describe him either. DDS may occur with all forms of DRT, but the addition of apomorphine often acts as a catalyst for the progression of the disorder ${ }^{4,8}$, suggesting that the drugs with faster onset of action tend to be a crucial factor in determining misuse of dopaminergic agents. In a similar way, punding is more common between those patients using subcutaneous apomorphine or fastacting formulations of levodopa ${ }^{16}$. It is uncertain whether the use of dopaminergic agonists, pramipexol and ropinirol, is related with a higher risk for DDS.
However, recent case series reported behavioral changes such as pathological gambling and hypersexuality in PD patients using these drugs ${ }^{17,18}$.

The DSM-IV diagnostic criteria for drug dependence were thought to be not adequately applicable to DDS as PD patients use medication due to a chronic medical condition. Nevertheless, PD patients with DDS fulfill the core operational criteria of drug dependence according to DSM-IV: they manifest tolerance, "withdrawal" and escalating doses as symptoms become more severe with disease progression or ph a rmacokinetic changes occur like wearing off ${ }^{4,8,13}$.

Dys regulation of brain dopamine systems mediating reward is proposed to underlie the development of DDS 4,15 . The PD patients with DDS may seek for artificial rewards to compensate their intrinsic rewa rd deficit due to dopaminergic hypoactivity in the basal ganglia. This basal ganglia hypoactivity occurs mainly in the off periods and seems to be worsened by compensatory neuronal changes induced by the chronic use of levodopa ${ }^{19}$.

Regions of both ventral and dorsal striatum have been implicated in the reinforcement for drug addiction. The nucleus accumbens (or ventral striatum) shell is supposed to mediate the psychomotor stimulus of dopaminergic drugs and its primary reinforeing effect, possibly, via descending neural influences over autonomic and motor responses. The nucleus accumbens core is thought to mediate the effects of the conditioned reinforcer. This is important to maintain seeking behavior in the presence of a drug associated conditioned stimulus, but in the absence of the drug itself. The dorsal striatum seems to mediate the development of habits, i.e. stimulus-response learning mechanisms with less involvement of the goal itself. The habit formation underlies some features of compulsive drug seeking and other stere otyped behavior like punding. The medial prefrontal cortex (mPFC) is another region affected in PD that receives dopaminergic innervation, and it is involved in rewardand addiction ${ }^{20}$. In PD, although dopamine rgic neurons of the ventral tegmental area that projects to nucleus accumbens, caudate and PFC may be a ffected in some patients, the dopaminergic proj ection from the pars compacta of the substantia nigra to the putamen is the most compromised circuit. This nigro-putamen circuit is also affected by levodopainduced neuronal changes. Perhaps, this could be an explanation for the low prevalence of addiction among PD patients ${ }^{19}$. It may be hypothesized that patients who are more prone to develop DDS, as the 
case reported here, have dopaminergic lesions pre $\mathrm{f}$ e rentially outside the nigro-putamen circuit. In conclusion, DDS, although rare, is of both clinical and theoretical importance.

Psychiatric symptoms often go unrecognized in PD although they are potentially treatable and may be important factor to the morbidity of the disease. Nevertheless, as highlighted by our case, they may become a real challenge for the clinician. Despite the first step in the treatment of psychiatric conditions in PD is the optimization of its treatment, the pro$g$ ression of PD turns it into a real Procust's bed: the control of motor symptoms can cause psychiatric symptoms and their treatment may worse neuro logical symptoms. Then, the quality of life in PD patients is indeed determined by non-motor symptoms as much as it is by the motor disorder itself ${ }^{21}$.

\section{REFERENCES}

1. Nutt JG, Wooten GF. Diagnosis and initial management of Parkinson's disease. N Engl J Med 2005;335:1021-1027.

2. Teixeira AL, Cardoso F. Tratamento inicial da doença de Parkinson. Rev Neurociências 2004;12:146-151.

3. Schrag A. Psychiatric aspects of Parkinson's disease: an update. J Neurol 2004;251:795-804.

4. Lawrence AD, Evans AH, Lees AJ. Compulsive use of dopamine replacement therapy in Parkinson's disease: reward systems gone awry? Lancet Neurol 2003;2:595-604.

5. Evans AH, Lees AJ. Dopamine dysregulation syndrome in Parkinson's disease. Curr Opin Neurol 2004;17:393-398.

6. Molina JA, Jiménez-Jiménez FJ, Ortí-Pareja M. Complicaciones motoras y psíquicas en el tratamiento prolongado con levodopa de la enfermedad de Parkinson complicada. Rev Neurol 1999;28:982-990.
7. Noé-Sebastián E, Irimia-Sieira P, Pomares-Arias E, Martinez-Vila E, Luquin-Piudo MR. Trastornos neuropsiquiátricos en la enfermedad de Parkinson. Rev Neurol 2001;32:676-681.

8. Giovannoni G, O'Sullivan JD, Turner K, Manson AJ, Lees AJ. Hedonistic homeostatic dysregulation in patients with Parkinson's disease on dopamine replacement therapies. J Neurol Neuro su rgPsychiatry 2000; 68:423-428.

9. Witjas T, Baunez C, Henry JM, et al. Addiction in Parkinson's disease: impact of subtalamic nucleus deep brain stimulation. Mov Disord 2005; 20:1052-1055.

10. Koob GF, Le Moal M. Drug abuse: hedonic homeostatic dysregulation. Science 1997;278:52-58.

11. Pezzella FR, Colosimo C, Vanacore N, et al. Prevalence and clinical features of hedonistic homeostatic dysregulation in Parkinson's disease. Mov Disord 2005;20:77-81.

12. Pezzella FR, Di Rezze $S$, Chianese M, et al. Hedonistic homeostatic dysregulation in Parkinson's disease: a short screening questionnaire. Neurol Sci 2003;24:205-206.

13. Bearn J, Evans A, Kelleher M, Turner K, Lees A. Recognition of a dopamine replacement therapy dependence syndrome in Parkinson's disease: a pilot study. Drug Alcohol Depend 2004;76:305-310.

14. Miwa H, Kondo T. Increased writing activity in Parkinson's disease: a punding-like behavior? Parkinsonism Relat Disord 2005;11:323-325.

15. Evans AH, Lawrence AD, Potts J, Appel S, Lees AJ. Factors influencing susceptibility to compulsive dopaminergic drug use in Parkinson's disease. Neurology 2005;65:1570-1574.

16. Evans AH, Katzenschlager R, Paviour D, et al. Punding in Parkinson's disease: its relation to the dopamine dysregulation syndrome. Mov Disord 2004;19:397-405.

17. Klos KJ, Bower JH, Josephes KA, Matsumoto JY, Ahlskog JE. Pathological hypersexuality predominantly linked to adjuvant dopamine agonist therapy in Parkinson's disease and multiple system atrophy. Parkinsonism Relat Disord 2005;11:381-386.

18. Dodd ML, Klos KJ, Bower JH, Geda YE, Josephes KA, Ahlskog JE. Pathological gambling caused by drugs used to treat Parkinson's disease. Arch Neurol 2005;62:1377-1381.

19. LinazasoroG, van Blercom N, Lasa A. Hipótesis: enfermedad de Parkinson, síndrome de deficiencia de recompensa y efectos adictivos de la levodopa. Neurologia 2004;19:117-127.

20. Everitt BJ, Robbins TW. Neural systems of reinforcement for drug addiction: from actions to habits to compulsion. Nat Neurosci 2005;8: 1481-1489.

21. Burn DJ. Depression in Parkinson's disease. Eur J Neurol 2002;9:44-54 